Psychological Medicine, 1983, 13, 231-238

Printed in Great Britain

\title{
EDITORIAL
}

\section{The aetiology of anorexia nervosa ${ }^{1}$}

\begin{abstract}
Anorexia nervosa is an intriguing illness: the fact that it affects mainly attractive, intelligent young women, the wilful starvation, the near delusional insistence that they look just right, the intensive fear of becoming fat, the obsession with food and cooking, the perfectionist attitude, the secretiveness, and then the periodic gorging and vomiting. It has inspired a large number of publications recently, but there has been no consensus among the research workers on its aetiology. Currently, there are six main theories, organized along different conceptual levels, that attempt to explain this curious phenomenon. They are logically not mutually exclusive. While they overlap to some degree, their main thrust and conceptualization are distinct. This editorial will review the recent findings.
\end{abstract}

\section{THE SOCIAL-CULTURAL THEORY}

Anorexia nervosa occurs much more commonly in females than in males (Beumont et al. 1972; Crisp \& Toms, 1972; Gull, 1874; Jones et al. 1980; Kendell et al. 1973; for a review of major series, see Hsu, 1980). It affects predominantly upper social class teenage girls in developed countries (Buhrich, 1981; Crisp et al. 1976; Jones et al. 1980; Miyai et al. 1975). Its incidence appears to be increasing (Duddle, 1973; Halmi, 1974; Jones et al. 1980; Kendell et al. 1973; Theander, 1970). Thus, social-cultural factors appear to be involved in the development of this disorder.

The importance of physical attractiveness in Western society is undeniable. In the female this attractiveness has taken the form of slimness. Several surveys indicated that the majority of young women are unhappy about their weight and want to be slimmer (Calden et al. 1959; Huenemann et al. 1966; Nylander, 1971). In contrast, men prefer to be bigger and heavier (Calden et al. 1959; Huenemann et al. 1966; Nylander, 1971). Garner et al. (1980), reviewing data from Playboy centrefolds and Miss America Pageant contestants in the last 20 years, found a significant trend towards slimness. All measurements of Playboy centrefold girls, except for height and waist, decreased significantly. Thus, for instance, the average Playmate in 1959 weighed $91 \%$ of average, while in 1978 they weighed only $83.5 \%$ of average. America pageant winners since 1970 , with a mean weight of only $82.5 \%$ of average, weighed significantly less than the average contestant. Meanwhile, the number of diet articles in six women's magazines has increased substantially over the last 20 years. However, Garner et al. (1980) found that this emphasis on thinness and dieting occurs in a population that is becoming heavier. Weight statistics from the Society of Actuaries over the last 20 years indicated an increase in the average weight in all height categories for women below the age of 30 years. The pressure on women, particularly those of the upper social class, to diet and appear slim thus seems relentless (Goldblatt et al. 1965; Halmi et al. 1978b). That such pressure may precipitate the development of anorexia nervosa seems to be confirmed by the finding that the condition is much more common in women who must rigorously control their size and shape - such as ballerinas, modelling students and athletes (Druss \& Silverman, 1979; Frisch et al. 1980; Garner \& Garfinkel, 1980). Competitiveness intensifies the pressure (Garner \& Garfinkel, 1980). Under such circumstances it is perhaps not surprising that Branch \& Eurman (1980) found that the anorectic's friends and relatives actually admired her slimness, specialness and control. Meanwhile, BoskindLodahl (1976) regarded the 'cultural heritage of sexual inequality' to be directly responsible for the development of eating disorders in women. However, since such inequality presumably also exists

\footnotetext{
' Address for correspondence: Dr L. K. George Hsu, Western Psychiatric Institute and Clinic, University of Pittsburgh, 3811 O'Hara Street, Pittsburgh, PA 15213, USA.
} 
in developing countries, it is difficult to see why the disorder is so rare in these countries (Buhrich, 1981). Palazzoli (Palazzoli, 1974; Palazzoli et al. 1977) emphasized the complex and contradictory roles which women had to play in modern society. Such role diffusion presumably increases insecurity and intensifies the striving for perfection and control.

That such social-cultural pressure generates a greater likelihood for the development of anorexia nervosa in women is probably not in dispute. It is, however, obvious that not all women exposed to such pressure develop anorexia nervosa. Other factors must also occur to precipitate the final development of the illness.

\section{FAMILY PATHOLOGY THEORY}

The early investigators have all emphasized the family pathology in anorexia nervosa (Charcot, 1889; Gull, 1874; Laseque, 1873). Charcot (1889) advocated the separation of the patient from her family as part of treatment. Gull (1874) found that the relatives were the worst attenders of the patient. Lasèque (1873) described the striking family enmeshment and he urged clinicians not to overlook the family pathology. Other early investigators have likewise described the adverse influence of the family on the patient (Crookshank, 1931; Young, 1931).

Attempts to identify a typical anorectic mother (Cobb, 1950; Kay \& Leigh, 1954; King, 1963; Nemiah, 1950) or a typical anorectic father (Groen \& Feldman-Toledo, 1966; King, 1963; Nemiah, 1950; Sours, 1981) have produced no consistent findings (Crisp et al. 1980; Kalucy et al. 1977). More recently, several authors have described a typical anorectic family interaction pathology. Bruch $(1973,1977)$ emphasized the facade of happiness and stability that hid a deep disillusionment and secret competition of the parents. She also found that the parents were very preoccupied with outward appearance and success. Palazzoli (1974) studied 12 anorectic families and found that a rejection of communicated message, poor conflict resolution, covert alliance of family members and blame shifting were characteristic of the anorectic family. She also emphasized their rigidity in that they tried to preserve agricultural-patriarchal values and mores in an urban-industrial setting. Both Palazzoli and Bruch found that the parents were overprotective but also involved the sick child in their covert competition and conflict. They seemed to use the child to discharge some of their own unfulfilled longings. Minuchin and his co-workers have written extensively on the psychosomatic family (Minuchin, 1974; Minuchin et al. 1975, 1978). They advocated an open systems model for psychosomatic illness, anorexia nervosa included. This system included parts such as extrafamilial stress, family organization and functioning, the vulnerable child, physiological and biochemical mediating mechanisms and the symptomatic child. The system could be activated at any point and the parts could affect each other. Nevertheless, these authors have emphasized almost exclusively the family pathology in this system and stated that 'When significant family interaction patterns are changed, significant changes in the symptoms of the psychosomatic illness also occur' (Minuchin et al. 1978, p. 21). They further hypothesized that: (1) certain family characteristics were related to the development and maintenance of psychosomatic symptoms in children; (2) the child's psychosomatic symptoms played a major role in maintaining family homeostasis. The family characteristics identified were enmeshment, overprotectiveness, rigidity and lack of conflict resolution. Meanwhile, the child was used to maintain stability and to avoid open conflict, and thus was often caught (triangulated) in the parents' covert conflict. The illness enabled the parents to submerge their conflicts in protecting or blaming the sick child, who was then defined as the sole family problem.

However, few studies exist to confirm that such family interaction pathology occurs in anorexia nervosa. Crisp et al. (1974) used a standardized measure (the Middlesex Hospital Questionnaire) and found that the psychoneurotic status of the parents worsened significantly as the patient's weight increased with treatment. This was particularly so if the marital relationship was poor. The six-month outcome for the patient's illness was significantly related to the initial parental psychoneurotic morbidity. Case selection factors and family therapy effects were, however, uncontrolled. Foster \& Kupfer (1975) telemetrically recorded the nocturnal motility of a female patient with anorexia 
nervosa and found that nocturnal activity was correlated with visits by specific family members during the previous day. Visits by the father and the identical twin led to a decrease in nocturnal motility, while visits by the mother and older sister led to an increase in such 'arousal'. The extent to which such findings can be generalized is, however, questionable.

Related to the issue of family environment is the role of genetic factors in the pathogenesis of anorexia nervosa. Several large-scale studies have found an increased incidence of anorexia nervosa in the family members of the patients (Crisp et al. 1980; Halmi et al. 1977; Morgan \& Russell, 1975; Theander, 1970). Monozygotic twin studies have found a concordance of about $50 \%$ (for a review, see Askevold \& Heiberg, 1979) but, to the best of our knowledge, no study on dizygotic twins has been reported. Adoptive studies, however, are needed to tease out environmental versus genetic factors. In this connection, Crisp \& Toms (1972) described a remarkable case of a male chronic anorectic whose adoptive son as well as the girl who stayed with the family as a war evacuee both developed anorexia nervosa. In sum, it remains to be substantiated that specific abnormal family interaction patterns occur in anorexia nervosa and that they are causally related to the development of the condition. Moreover, most of the studies quoted ignored the effect of this exasperating illness on family interaction and thus failed to distinguish between family pathology occurring as stress reactions as opposed to pre-existing patterns (Yager, 1982). The need for well-controlled direct observation studies of family interaction is obvious.

Finally, Crisp and his co-workers have suggested that family weight pathology may be specifically related to the pathogenesis of the illness (Crisp, 1977; Kalucy et al. 1977). In a well-controlled study of the parents of anorectic patients, Halmi et al. (1978 b) failed to confirm this.

\section{INDIVIDUAL PSYCHODYNAMIC THEORY}

Psychoanalytic studies of anorexia nervosa have been reviewed by Sours (1974) and Bemis (1978). Both Bruch (1970) and Palazzoli (1974) have found that the psychoanalytic approach was relatively ineffective. In 1931, Brown observed that anorexia nervosa was a pathological manifestation of the detachment of the growing individual from parental authority. Bruch $(1962,1970,1973,1977)$ has repeatedly stated that anorexia nervosa was a struggle for a self-respecting identity. That such a struggle took the form of wilful starvation suggested serious psychological development defects. Central to such defects was the failure of the parents to regard the patients as individuals in their own right; they failed to transmit a sense of competence and self-value to their children. The youngsters were instead treated as something to complement the parents' needs. Their sense of worth and value were thus deprived from being needed by each parent. In short, they felt that they were the property of their parents. The illness thus represented an effort to escape from such a role and to establish control. Because of their disturbed perception of bodily sensation related to their lack of autonomy, and a paralysing sense of ineffectiveness, such patients misinterpreted their biological functioning and social role, and came to interpret thinness and starvation as specialness and self-control in an exaggerated and concrete way. Palazzoli (1974) and Boskind-Lodahl (1976) echoed such views.

The individual psychodynamic theory is extremely plausible, except that it has never been tested empirically. A recent single case study (Rampling, 1980) provided some evidence of abnormal mothering in a case of a male anorectic subject.

\section{THE DEVELOPMENTAL PSYCHOBIOLOGICAL THEORY}

Brown (1931) stated that a fear of growing up and assuming adult responsibility was highly characteristic of anorectics. Crisp has repeatedly stated (Crisp, 1967, 1970, 1977) that anorexia nervosa was rooted in the biological and consequently experiential aspects of normal adult weight. Starvation in the anorectic represented a phobic avoidance of adolescent/adult weight. Anorexia nervosa was thus a disorder of weight pivoting around specific maturational changes of puberty, both biological and psychological. The psychobiological regression reflected the individual's need 
to avoid adolescent and related family turmoil. The severe dieting was reinforced by the relief that the control and the low weight brought, as biological and related psychological childhood was re-experienced and post-pubertal experience was concurrently eliminated. Meanwhile, adolescence in the child threatened the rigid and experience-denying parents. The illness thus sometimes served to avert rekindling of buried and denied but unresolved parental conflicts and psychopathology. Needless to say, the illness brought its own problems but they were deemed to be the price that the patient and her family had to pay the avoid deeper, more fundamental discord. Crisp has repeatedly emphasized that such maturational demands of adolescence and family pathology were not specific to the condition. Indirect and partial support for this view has come from several sources: (1) the immature pattern of gonadotrophin release in anorectics which reverts to normal after weight gain (Boyar et al. 1974; Katz et al. 1978); (2) Frisch (1972, 1977) has found that puberty hinges on the individual attaining a critical amount of fatness; (3) clinical experience suggests that anorectics will often agree to eat provided that weight gain does not occur, thereby indicating that weight rather than eating is involved in the issue of control; (4) finally, Crisp et al.'s (1974) finding that the parents' psychoneurotic status worsened following the patient's recovery seems to support the notion that the illness serves to reduce family tension. Nevertheless, this theory of 'weight phobia' has never been tested empirically. One study found that anorexia nervosa patients differed from other phobic patients in terms of skin conductance changes (Salkind et al. 1980).

\section{PRIMARY HYPOTHALAMIC DYSFUNCTION THEORY}

Russell $(1965,1970,1977 a)$ has repeatedly suggested that a primary hypothalamic dysfunction of unknown aetiology and only partially dependent on weight loss and psychopathology occurred in anorexia nervosa. An early onset of amenorrhoea often occurs before any appreciable weight loss (for a review, see Bemis, 1978). This, in addition to the incomplete recovery of hypothalamic function and the persistent amenorrhoea despite weight gain, has been cited as evidence for a primary hypothalamic disorder (Katz et al. 1978; Russell, 1977a). Furthermore, several reports of hypothalamic tumour presenting as anorexia nervosa have appeared and the hypothalamus has traditionally been regarded as the central anatomical structure regulating feeding and satiety (for a review, see Mawson, 1974).

The role of the hypothalamus in the regulation of feeding and satiety is complex, and the importance of extra hypothalamic controls of feeding is increasingly recognized (McHugh \& Moran, 1977; Morrison, 1977; Stricker, 1978). Others, however, have maintained that increased biological satiety might cause anorexia nervosa (Redmond et al. 1977). In fact, most anorectics experience hunger and crave food and thus to postulate that they are satiated seems contrary to existing evidence. The concurrent onset of amenorrhoea and weight loss has been reported to occur in 30-60\% of patients (Beck \& Brøckner-Mortensen, 1954; Dally, 1969; King, 1963; Morgan \& Russell, 1975), but the figures were lower in other series (Crisp et al. 1980; Halmi et al. 1977; Theander, 1970). Amenorrhoea preceding the onset of any weight loss occurred in 7\% (Theander, 1970) to $25 \%$ (Kay \& Leigh, 1954; King, 1963) of cases. While such discrepancies may appear puzzling, one has to recognize the inherent difficulties involved in gathering retrospective data from anorectic patients, particularly a reliable dietary history (Crisp \& Stonehill, 1971). This was well illustrated by the study of Beumont et al. (1981). Two patients in their series had initially indicated that amenorrhoea occurred before weight loss, but careful history-taking found that months of chaotic eating had preceded the amenorrhoea.

Various explanations have been offered for the incomplete recovery of hypothalamic function in women with apparently healthy weight following anorexia nervosa. (1) Amenorrhoea occurred in non-anorectic women who had lost 10-15\% of normal weight for height (Frisch \& McArthur, 1974), and menstrual cycles often failed to return unless a critical threshold weight was exceeded (Frisch, 1977). Simple weight loss itself could lead to hypothalamic dysfunction (Vigersky et al. 1977) and immature LH secretory pattern (Kapen et al. 1981). Crisp \& Stonehill (1971) have suggested that the restoration of matched population mean weight rather than ideal weight was often necessary 
for menstruation to resume, particularly in patients who have been premorbidly obese. This view was partially supported by Knuth et al. (1977), who studied a group of 39 women with amenorrhoea due to loss of weight, including 24 with a diagnosis of anorexia nervosa. All patients were encouraged to gain weight and 14 who gained weight significantly (mean $3.6 \mathrm{~kg}$ ) resumed ovulatory menstrual cycles. In contrast, there was no significant weight gain in the 25 patients who remained amenorrhoeic (mean $0.7 \mathrm{~kg}$ ). (2) Many apparently recovered anorectics continue to starve, binge, vomit and purge (Cantwell et al. 1977; Hsu et al. 1979; Morgan \& Russell, 1975). Some may selectively avoid carbohydrates. Thus dietary behaviour may determine whether hypothalamic function returns to normal (Katz et al. 1978). It may, of course, be argued that such dietary disturbances reflect the primary hypothalamic disorder (Russell, 1977a). This issue cannot be resolved on current evidence. (3) There is some evidence to suggest that the recovery of hypothalamic function occurred in sequence and full recovery took time (Wakeling et al. 1977). However, in the study by Wakeling et al. (1977) only 3 out of 7 patients who maintained their weight over a 6-month period menstruated, but it was unclear whether the patients were at or above their average weight. In sum, it remains possible that a primary hypothalamic disorder exists in anorexia nervosa. Further studies are obviously necessary to clarify the situation.

\section{IS ANOREXIA NERVOSA RELATED TO AFFECTIVE DISORDER?}

Cantwell et al. (1977) have recently stated that anorexia nervosa may be an atypical affective disorder occurring in an adolescent female at a time in her life when body image issues were important. Two findings in their study supported this view: an increased incidence of affective disorder in the family; and, on long-term follow-up, the anorectics were more prone to develop affective disorder than to suffer a relapse of the eating disorder. Using well-defined criteria, Winokur et al. (1980) found that $22 \%$ of the relatives of anorectic probands had a history of primary affective disorder, an incidence similar to that reported in families of primary affective disorder patients. A family history of alcoholism, reported to be increased in some affective disorder patients (Winokur et al. 1978), also appeared to be increased in anorectic patients (Cantwell et al. 1977). However, Winokur et al. (1980) failed to confirm this. Certain biological markers have recently been reported for primary affective disorder, such as high plasma cortisol level (Sachar et al. 1970), dexamethasone non-suppression (Carroll, 1982), and low urinary 3-methoxy-4-hydroxyphenylglycol (Schildkraut et al. 1973). All of these changes also occurred in some anorectics, but the abnormalities were apparently reversible with weight gain (Gerner \& Gwirtsman, 1981; Gross et al. 1979; Halmi et al. 1978a; Walsh et al. 1981; Walsh, 1982). Characteristic sleep EEG findings have been reported for primary affective disorder (Kupfer et al. 1976; Feinberg et al. 1982). The changes were, however, different from those reported in anorexia nervosa patients (Neil et al. 1980). Meanwhile, anorectics were not as overtly depressed as patients with affective disorder (Bentovim et al. 1979; Crisp et al. 1978; Eckert et al. 1982). Most follow-up studies suggested that anorexia nervosa' 'breeds true' (Hsu et al. 1979; Morgan \& Russell, 1975; Russell, 1970). Cantwell et al.'s (1977) findings that anorexia nervosa patients were more likely to suffer from an affective disorder than anorexia nervosa at follow-up may be related to methodological issues in their study (Hsu, 1980). Finally, anecdotal reports of the usefulness of antidepressants in the treatment of anorexia nervosa (Mills, 1976; Needleman \& Waber, 1977) have not been widely accepted (Crisp et al. 1980; Russell, 1977b). The complex relationship between the two disorders deserves wider study.

\section{CONCLUSION}

While it is possible that anorexia nervosa has a single discrete cause, it is equally possible that complex chains of events interact to precipitate the illness. Kendell (1975) clearly favoured the latter view for psychiatric diseases in general. He even stated that: "The very idea of "cause" has become meaningless, other than as a convenient designation for the point in the chain of event sequences at which intervention is most practicable' (p. 64). The overlap of the theories reviewed above 
certainly suggests that this argument is at least plausible in the case of anorexia nervosa. If this is so, the challenge then will be to identify such events and how they interact. Needless to say, such events may include some or all of the proposed aetiological factors already reviewed, or none of them. A possible strategy may be to study prospectively and follow-up a group of youngsters considered to be at risk for developing the illness - for example, professional dance and modelling students. The logistical and ethical problems involved in such a study may, however, be prohibitive.

L. K. GEORGE HSU

\section{REFERENCES}

Askevold, F. \& Heiberg, A. (1979). Anorexia nervosa: two cases in discordant MZ twins. Psychotherapy and Psychosomatics 32, 223-228.

Beck, J. C. \& Brechner-Mortenson, K. (1954). Observations on the prognosis in anorexia nervosa. Acta Medica Scandinavica 149, $409-430$.

Bemis, K. M. (1978). Current approaches to the etiology and treatment of anorexia nervosa. Psychological Bulletin 85, 593-617.

Bentovim, D. I., Marilov, V. \& Crisp, A. H. (1979). Personality and mental state (PSE) with anorexia nervosa. Journal of Psychosomatic Research 23, 321-325.

Beumont, P. J. V., Beardwood, C. J. \& Russell, G. F. M. (1972). The occurrence of anorexia nervosa in male subjects. Psychological Medicine 2, 216-231.

Beumont, P. J. V., Abraham, S. F. \& Simson, K. G. (1981). The psychosexual histories of adolescent girls and young women with anorexia nervosa. Psychological Medicine 11, 477-484.

Boskind-Lodahl, M. (1976). Cinderella's stepsisters: a feminist perspective on anorexia nervosa and bulimia. Signs: Journal of Women in Culture and Society 2, 342-356.

Boyar, R. N., Katz, J., Finkelstein, J. W., Kapen, S., Weiner, H., Weitzman, E. D. \& Hellman, L. (1974). Anorexia nervosa: immaturity of the 24 hour luteinizing hormone secretory pattern. New England Journal of Medicine 291, 861-865.

Branch, C. H. H. \& Eurman, L. K. (1980). Social attitudes toward patients with anorexia nervosa. American Journal of Psychiatry 137, 632-633.

Brown, W. L. (1931). Anorexia nervosa. In Anorexia Nervosa (ed. W. L. Brown), pp. 11-18. C. W. Daniels: London.

Bruch, H. (1962). Perceptual and conceptual disturbances in anorexia nervosa. Psychosomatic Medicine 24, 187-194.

Bruch, H. (1970). Psychotherapy in primary anorexia nervosa. Journal of Nervous and Mental Disease 150, 51-67.

Bruch, H. (1973). Eating Disorders. Basic Books: New York.

Bruch, H. (1977). Psychological antecedents of anorexia nervosa. In Anorexia Nervosa (ed. R. A. Vigersky), pp. 1-10. Raven Press: New York.

Buhrich, N. (1981). Frequency of presentation of anorexia in Malaysia. Australian and New Zealand Journal of Psychiatry 15, 153-155.

Calden, G., Lundy, R. M. \& Schlafer, R. J. (1959). Sex differences in body concepts. Journal of Consulting Psychiatry 23, 378.

Cantwell, D. P., Sturzenberger, S., Borroughs, J., Salkin, B. \& Green, J. K. (1977). Anorexia nervosa - an affective disorder? Archives of General Psychiatry 34, 1087-1093.

Carroll, B. J. (1982). The dexamethasone suppression test for melancholia. British Journal of Psychiatry 140, 292-304.

Charcot, J. M. (1889). Disorders of the Nervous System. New Sydenham Society: London.

Cobb, S. (1950). Emotions and Clinical Medicine. Norton: New York.

Crisp, A. H. (1967). Anorexia nervosa. Hospital Medicine 1, 713-718.

Crisp, A. H. (1970). Anorexia nervosa: feeding disorder, nervous malnutrition or weight phobia? World Review of Nutrition and Diet 12, 452-504.

Crisp, A. H. (1977). Diagnosis and outcome of anorexia nervosa. Proceedings of the Royal Society of Medicine 70, 464-470.

Crisp, A. H. \& Stonehill, E. (1971). Relation between aspects of nutritional disturbance and menstrual activity in primary anorexia nervosa. British Medical Journal ii, 149-151.

Crisp, A. H. \& Toms, D. A. (1972). Primary anorexia nervosa or weight phobia in the male. British Medical Journal i, 334-338.

Crisp, A. H., Harding, B. \& McGuinness, B. (1974). Anorexia nervosa: psychoneurotic characteristics of parents: relationship to prognosis. Journal of Psychosomatic Research 18, 167-173.

Crisp, A. H., Palmer, R. L. \& Kalucy, R. S. (1976). How common is anorexia nervosa? A prevalence study. British Journal of Psychiatry $128,549-554$.

Crisp, A. H., Jones, M. G. \& Slater, P. (1978). The Middlesex Hospital Questionnaire, a validity study. British Journal of Medical Psychology 51, 269-280.

Crisp, A. H., Hsu, L. K. G., Harding, B. \& Hartshorn, J. (1980). Clinical features of anorexia nervosa. Journal of Psychosomatic Research 24, 179-191.

Crookshank, F. G. (1931). Anorexia nervosa. In Anorexia Nervosa (ed. W. L. Brown), pp. 19-40. C. W. Daniel: London.

Dally, P. (1969). Anorexia Nervosa. Heinemann, London.

Druss, R. G. \& Silverman, J. A. (1979). Body image and perfectionism of ballerinas. General Hospital Psychiatry 2, 115-121.

Duddle, M. (1973). An increase of anorexia nervosa in a university population. British Journal of Psychiatry 123, 711-712.

Eckert, E. D., Goldberg, S. C., Halmi, K. A., Casper, R. C. \& Davis, J. M. (1982). Depression in anorexia nervosa. Psychological Medicine 12, 115-122.

Feinberg, M., Gillin, J. C., Carroll, B. J., Greden, J. F. \& Zis, A. P. (1982). EEG studies of sleep in the diagnosis of depression. Biological Psychiatry 17, 305-316.

Foster, F. G. \& Kupfer, D. J. (1975). Anorexia nervosa: telemetric assessment of family interactions and hospital events. Journal of Psychosomatic Research 12, 19-35.

Frisch, R. E. (1972). Weight in menarche. Pediatrics S0, 445-450.

Frisch, R. E. (1977). Food intake, fatness and reproductive ability. In Anorexia Nervosa (ed. R. A. Vigersky), pp. 149-162. Raven Press: New York.

Frisch, R. E. \& McArthur, J. W. (1974). Menstrual cycles: fatness as a determinant of minimum weight for the height necessary for their maintenance or onset. Science 185, 949-951.

Frisch, R. E., Wyshak, G. \& Vincent, L. (1980). Delayed menarche and amenorrhea in ballet dancers. New England Journal of Medicine 303, 17-19.

Garner, D. M. \& Garfinkel, P. E. (1980). Social cultural factors in the development of anorexia nervosa. Psychological Medicine 10, 647-656.

Garner, D. M., Garfinkel, P. E., Schwartz, D. \& Thompson, M. (1980). Cultural expectations of thinness in women. Psychological Reports 47, 483-491.

Gerner, R. H. \& Gwirstman, H. E. (1981). Abnormalities of dexamethasone suppression test and urinary MHPG in anorexia nervosa. American Journal of Psychiatry 138, 650653.

Goldblatt, P. B., Moore, M. E. \& Stunkard, A. J. (1965). Social factors in obesity. Journal of the American Medical Association 192 , 97-102.

Groen, J. J. \& Feldman-Toledano, Z. (1966). Educative treatment of patients and parents in anorexia nervosa. British Journal of Psychiatry 112, 671-681. 
Gross, H. A., Lake, C. R., Eber, M. H., Hegler, M. G. \& Kopin, I. J. (1979). Catecholamine metabolism in primary anorexia nervosa Journal of Clinical Endocrinological Metabolism 49, 805-809.

Gull, Sir W. (1874). Anorexia nervosa (apepsia hysterica, anorexia hysterica). Transactions of the Clinical Society, London 7, 22-28.

Halmi, K. A. (1974). Anorexia nervosa: demographic and clinical features in 94 cases. Psychosomatic Medicine 36, 18-26.

Halmi, K. A., Goldberg, S. C., Eckert, E., Casper, R. \& Davis, J. M. (1977). Pretreatment evaluation in anorexia nervosa. In Anorexia Nervosa (ed. R. A. Vigersky), pp. 43-54. Raven Press: New York.

Halmi, K. A., Dekirmenjian, H., Davis, J. M., Casper, R. \& Goldberg, S. C. $(1978 a)$. Catecholamine metabolism in anorexia nervosa. Archives of General Psychiatry 35, 458-460.

Halmi, K. A., Struss, A. \& Goldberg, S. C. (1978b). An investigation of weights in parents of anorexia nervosa patients. Journal of Nervous and Mental Disease 166, 358-361.

Hsu, L. K. G. (1980). Outcome of anorexia nervosa. Archives of General Psychiarry 37, 1041-1046.

Hsu, L. K. G., Crisp, A. H. \& Harding, B. (1979). Outcome of anorexia nervosa. Lancet i, 61-65.

Huenemann, R. L., Shapiro, L. R., Hampton, M. C. \& Mitchell, B. W. (1966). A longitudinal study of gross body composition and body conformation and their association with food and activity in a teenage population. American Journal of Clinical Nutrition 18 , 324-338.

Jones, D. J., Fox, M. M., Babigian, H. M. \& Hutton, H. E. (1980). Epidemiology of anorexia nervosa in Monroe County, New York: 1960-1976. Psychosomatic Medicine 42, 551-558.

Kalucy, R., Crisp, A. H. \& Harding, B. (1977). A study of 56 families with anorexia nervosa. British Journal of Medical Psychology 50, 381-395.

Kapen, S., Sternthal, E. \& Braverman, L. (1981). A 'pubertal' 24-hour luteinizing hormone secretory pattern following weight loss in the absence of anorexia nervosa. Psychosomatic Medicine 43, 177-182.

Katz, J. L., Boyar, R., Roffwarg, H., Hellman, L. \& Weiner, H. (1978). Weight and circadian luteinizing hormone secretory pattern in anorexia nervosa. Psychosomatic Medicine 40, 549-567.

Kay, D. W. K. \& Leigh, D. (1954). The natural history, treatment and prognosis of anorexia nervosa, based on a study of 38 patients. Journal of Mental Science 100, 4l $1-431$.

Kendell, R. E. (1975). The Role of Diagnosis in Psychiatry. Blackwell: Oxford.

Kendell, R. E., Hall, D. J., Hailey, A. \& Babigian, H. M. (1973). The epidemiology of anorexia nervosa. Psychological Medicine 3, 200-203.

King, A. (1963). Primary and secondary anorexia nervosa. British Journal of Psychialry 109, 470-479.

Knuth, V. A., Hull, M. G. R. \& Jacobs, H. S. (1977). Amenorrhoea and loss of weight. British Journal of Obstetrics and Gynaecology 84, 801-807.

Kupfer, D. J., Thompson, K. S. \& Weiss, B. (1976). EEG sleep changes as predictors in depression. American Journal of Psychiatry $133,622-626$.

Laseque, C. (1873). On hysterical anorexia. Medical Times Gazelte 2, 265-367.

Mawson, A. R. (1974). Anorexia nervosa and the regulation of intake: a review. Psychological Medicine 4, 289-308.

McHugh, P. R. \& Moran, T. H. (1977). An examination of the concept of satiety in hypothalamic hyperphagia. In Anorexio Nervosa (ed. R. A. Vigersky), pp. 67-74. Raven Press: New York.

Mills, I. H. (1976). Amitriptyline therapy in anorexia nervosa. Lancet ii, 687.

Minuchin, S. (1974). Families and Family Therapy. Harvard University Press: Cambridge, Mass.

Minuchin, S., Baker, L., Rosman, B. L., Liebman, R., Milman, L. \& Todd, T. (1975). A conceptual model of psychosomatic illness in children. Archives of General Psychiatry 32, 1031-1038.

Minuchin, S., Rosman, B. L. \& Baker, L. (1978). Psychosomatic Families: Anorexia Nervosa in Context. Harvard University Press: Cambridge, Mass.
Miyai, K., Yamamoto, T., Azukizawa, M., Ishibashi, K. \& Kumahara, Y. (1975). Serum thyroid hormones and thyrotropin in anorexia nervosa. Journal of Clinical Endocrinology and Metabolism 40, 334-338.

Morgan, H. G. \& Russell, G. F. M. (1975). Value of family background and clinical features as predictors of long-term outcome in anorexia nervosa: four-year follow-up study of 41 patients. Psychological Medicine 5, 355-371.

Morrison, S. D. (1977). Extrahypothalamic controls of feeding. In Anorexia Nervosa (ed. R. A. Vigersky), pp. 75-80. Raven Press: New York.

Needleman, H. L. \& Waber, D. (1977). The use of amitriptyline in anorexia nervosa. In Anorexia Nervosa (ed. R. A. Vigersky) pp. 357-362. Raven Press: New York.

Neil, J. F., Merikangas, J. R., Foster, F. G., Merikangas, K. R., Spiker, D. G. \& Kupfer, D. J. (1980). Waking and all night EEG in anorexia nervosa. Clinical Electroencephalography 11, 9-15.

Nemiah, J. C. (1950). Anorexia nervosa. Medicine 29, 225-268.

Nylander, I. (1971). The feeling of being fat and dieting in a school population. Acta Sociomedica Scandinavica 3, 17-26.

Palazzoli, M. S. (1974). Self-Starvation. Jason Aronson: New York.

Palazzoli, M. S., Boscolo, L., Cecchin, G. F. \& Prata, G. (1977). Family rituals: a powerful tool in family therapy. Family Process 16, 445-453.

Rampling, D. (1980). Abnormal mothering in the genesis of anorexia nervosa. Journal of Nervous and Mental Disease 168, 501-504.

Redmond, D. E., Snyder, D. R.\& Maas, J. W. (1977). Norepinephrine and satiety in monkeys. In Anorexia Nervosa (ed. R. A. Vigersky), pp. 81-96. Raven Press: New York.

Russell, G. F. M. (1965). Metabolic aspects of anorexia nervosa. Proceedings of the Royal Society of Medicine 58, 811-814.

Russell, G. F. M. (1970). Anorexia nervosa - its identity as an illness and its treatment. In Modern Trends in Psychological Medicine, Vol. 2 (ed. J. H. Price), pp. 131-164. Butterworth: London.

Russell, G. F. M. (1977a). The present status of anorexia nervosa. Psychological Medicine 7, 353-367.

Russell, G. F. M. (1977b). General management of anorexia nervosa and difficulties in assessing the efficiency of treatment. In Anorexia Nervosa (ed. R. A. Vigersky), pp. 277-290. Raven Press: New York.

Sachar, E. J., Hellman, L., Fukushima, D. K. \& Gallagher, T. F. (1970). Cortisol production in depressive illness. Archives of General Psychiatry 23, 289-298.

Salkind, M. R., Fincham, J. \& Silverstone, T. (1980). Is anorexia nervosa a phobic disorder? Biological Psychiatry 15, 803-808.

Schildkraut, J. J., Keeler, B. A. \& Papousek, M. (1973). MHPG excretion in depressive disorders. Science 181, 762-764.

Sours, J. A. (1974). The anorexia nervosa syndrome. International Journal of Psychoanalysis 55, 567-576.

Sours, J. A. (1981). Depression and the anorexia nervosa syndrome. Pediatric Clinics of North America 4, 145-158.

Stricker, E. (1978). Hyperphagia. New England Journal of Medicine 298, 1010-1012.

Theander, S. (1970). Anorexia nervosa : a psychiatric investigation of 94 female patients. Acta Psychiatrica Scandinavica, Supplement 214.

Vigersky, R. A., Anderson, A. E., Thompson, R. H. \& Loriaux, L. (1977). Hypothalamic dysfunction in secondary amenorrhea associated with simple weight loss. New England Journal of Medicine 297, 1141-1145.

Wakeling, A., DeSouza, V. A. \& Beardwood, C. J. (1977). Assessment of negative and positive feed back effects of administered oestrogen on gonadotrophin release in patients with anorexia nervosa. Psychological Medicine 7, 397-405.

Walsh, B. T. (1982). Endocrine disturbances in anorexia nervosa and depression. Psychosomatic Medicine 44, 85-91.

Walsh, B. T., Katz, J. L., Levin, J., Kream, J., Fukushima, D. K., Weiner, H. \& Zumoff, B. (1981). The production rate of cortisol declines during recovery from anorexia nervosa. Journal of Clinical Endocrinology and Metabolism 53, 203-205. 